\title{
Organização política regional na América-Latina: ne- cessidade específica ou escolha caprichosa?
}

\section{Political and regional organization on Latin America: specifical necessity or capricious choice?}

\section{Luciano Giambarresi Ganho ${ }^{[\mathrm{a}]}$, Rafael Weiss Brandt ${ }^{[\mathrm{b}]}$}

[a] Advogado. Bacharel em Direito pela Faculdade de Direito de Curitiba - UNICURITIBA. Pesquisador nas áreas de filosofia do Direito e Teoria do Estado. Curitiba, PR-Brasil, email: lucianoganho@gmail.com.

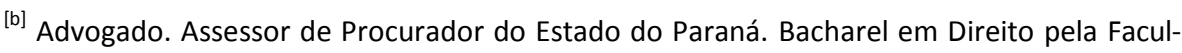
dade de Direito de Curitiba - UNICURITIBA. Pesquisador em Filosofia do Direito. Curitiba, PR-Brasil, e-mail: wbrandt@borgesmanica.com.br.

\section{Resumo}

O presente artigo pretende estudar a relação entre a globalização e seus efeitos sobre o Estado-nação. A partir destes elementos propor a viabilização de organizações políticas supranacionais no plano regional Latino-Americano, que contenham em sua estrutura instrumentos de participação democrática e de controle das decisões por meio dos cidadãos, de forma a viabilizar o exercício da cidadania, evitando a submissão das decisões internacionais às lógicas meramente econômicas. 
Palavras-chave: Filosofia política. Filosofia da libertação. Federalismo externo. Globalização. Analética.

\begin{abstract}
The present paper intends to present a study about the relationship between globalization and your effects on the Nation-state. From these elements propose the feasibility of supranational political organizations in Latin American regional plan, containing in this structure opportunities for democratic participation and control of decisions by citizens, in order a facilitate the exercise of citizenship, thus avoiding the submission of international decisions to merely economic logic.
\end{abstract}

Keywords: Political philosophy. Philosophy of liberation. External federalism. Globalization. Alterity.

\title{
1. Introdução
}

Durante a modernidade o Estado nacional/territorial conseguiu com a melhor efetividade organizar as sociedades, primeiro na forma de reinos e depois sob a forma de repúblicas e monarquias parlamentaristas, inclusive por demonstrar-se o modelo mais adequado ao desenvolvimento da economia capitalista, ainda que esta organização tenha custado à opressão e exclusão das minorais. ${ }^{1}$

Contudo, tal modelo tem sido abalado, conforme apontam discussões de Boaventura de Sousa Santos, Zygmunt Bauman e Jürgen Haber-

\footnotetext{
${ }^{1}{ }^{1}$ Segundo Habermas “Na Europa moderna, a forma pré-moderna de um império que une muitos povos, tal como aconteceu no velho Sacro Império Romano Germânico ou nos impérios russo e otomano, conseguiu estabilizar-se. Uma segunda forma surgiu nas periferias de cidades da Europa Central, assumindo estrutura federativa. Na Suíça, desenvolveu-se uma federação suficientemente forte para compensar as pretensões étnicas de uma associação multicultural de cidadãos. Entretanto, somente a terceira forma, a do Estado territorial, administrado por um poder central, conseguiu estruturar, a longo prazo, o sistema dos Estados europeus. No início, ele assumiu forma de reinos: Portugal, Espanha, França, Inglaterra e Suécia; mais tarde, ele se configurou como Estado nacional, fruto da democratização provocada pelo modelo francês. Essa formação estatal assegurou condições propícias ao desenvolvimento, em escala mundial, do sistema econômico capitalista. (...)O Estado nacional configurou a infra-estrutura para uma administração disciplinada pelo direito, além de oferecer a garantia para um espaço de ação individual e coletiva, livre do Estado. E, o que nos interessa especialmente, ele criou a base para homogeneidade cultural e ética que permitiu, desde o final do século XVIII, a democratização do aparelho do Estado - mesmo que às custas da opressão e da exclusão das minorias nacionais." (HABERMAS, 2003, p. 281)
} 
mas, com a fragilização do Estado nacional em seu poder político - realizado em âmbito local -, face os demais poderes articulados globalmente, abrindo espaço para a investigação de novas formas de realização política.

Tal constatação da submissão da política à economia também pode ser vista desde há tempos na periferia do mundo, isto é, nas nações por assim dizer - não contempladas pelo eixo nortista como "de primeiro mundo".

Neste sentido, novas formas de organizações políticas de caráter supranacional deverão surgir, dando origem a novas maneiras de se conceber as instituições e a democracia em âmbito regional, as quais deverão ser pautadas pela participação política não homogeneizadora sob o ponto de vista étnico-cultural, mas sim pela capacidade de criar uma cultura política inclusiva e apta a perseverar em uma sociedade plural.

\section{Paradigma da linguagem e totalização como mal-ético e a possi- bilidade de pautar a democracia a partir da analética}

Inicialmente cumpre pontuar que a filosofia da linguagem, como desenvolvimento de uma concepção filosófica-hermenêutica, sedimentando-se sobre a superada filosofia da consciência ${ }^{2}$, consolida-se de fato como o novo paradigma bastante abordado na academia.

Assim, rompeu-se com a noção de que as relações de compreensão de fenômenos e coisas dão-se diretamente na relação sujeito-objeto. Tal pode ser entendido pela exposição realizada na obra de Lenio Streck, fortemente amparada pela filosofia da linguagem no pensamento Heideggeriano.

\footnotetext{
Lenio Luiz Streck expõe sucintamente o rompimento com a filosofia da consciência, ainda que no campo do direito, argüindo que "A passagem de (e/ ou o rompimento com) um modelo de interpretação do Direito de cunho objetivista, reprodutivo, de visível influencia bettiana, que trabalha com a possibilidade da busca de conceitos ensimesmados das palavras da lei, feitas por um sujeito cognoscente mergulhado nos confins do paradigma epistemológico, da filosofia da consciência, começa $a$ ser feita a partir dos aportes da Semiótica, em sua matriz pragmática, e da hermenêutica filosófica, com a hermenêutica antirreprodutiva de Gadamer, pela qual se passa da percepção à compreensão." (STRECK, 2004, p. 178)
} 
A verdade possível (lembrando que o $§ 7^{0}$ de Ser e Tempo coloca a possibilidade acima da realidade) é aquilo que pode ser chamada de verdade hermenêutica: um tipo de verdade que se dá na clivagem entre "consciência e mundo" que aparece descrita brilhantemente no conceito de ser-no-mundo de Heidegger. Vale dizer: a verdade não é nem uma essência do objeto nem uma construção da consciência, mas, sim, o produto de uma compreensão afetivamente situada do ser-aí (Daisen). [...] De todo modo, é possível resumir isso na seguinte sentença: a verdade não é o resultado da construção de um sujeito consciente, mas sim, aquilo que emerge de uma compreensão lingüística e historicamente situada. (STRECK, 2012, p. 125-154)

Note-se que neste contexto a construção de determinada verdade se dá na concepção de que o sujeito está inserido em determinado universo, em que se conceitua ser-no-mundo, e não mais na essência do objeto e nem na consciência de determinado indivíduo. Assim, como demonstrado, "emerge de uma compreensão lingüística e historicamente situada."

A compreensão, a partir de Heidegger, passa a ser concebida em um contexto intersubjetivo de significação. ${ }^{3}$ Esta intersubjetividade propicia a compreensão vinculada ao mundo e aos outros seres-aí (também inseridos em um contexto intersubjetivo), nestes casos, por exemplo, o julgar (do magistrado) passa a não ser concebido como um ato de vontade, mas um ato de compreensão do universo em que está inserido e que tem sido denominado de círculo hermenêutico.

Como bem assinala Gadamer (Wahrheit und Methode I..., cit.), o que Heidegger diz aqui não é, em primeiro lugar, uma exigência à práxis da compreensão, mas descreve como forma de realização da própria interpretação compreensiva. A reflexão hermenêutica de Heidegger tem o seu ponto alto não no fato de demonstrar que aqui prejaz um círculo, mas que este círculo tem um sentido ontológico positivo. A descrição como

3 Streck ressalta a colaboração de Heidegger no rompimento com a construção solipsista da verdade, passando-se a conceber a fundamentação intersubjetiva, que "com o giro ontológico operado por Heidegger, dá-se - de forma inédita em toda a tradição filosófica - uma reconciliação entre prática e teoria e, ao mesmo tempo, ocorre uma deslocamento do solipsismo subjetivista para um contexto intersubjetivo de fundamentação." (STRECK, 2011, p. 455-456). 
tal será evidente para qualquer intérprete que saiba o que faz. Toda interpretação correta tem que proteger-se da arbitrariedade de intuições repentinas, enfim, dos preconceitos e voltar seu olhar para as "coisas elas mesmas" [...]. Por este motivo, diz Gadamer, a compreensão somente alcança sua verdadeira possibilidade quando as opiniões prévias com as quais inicia não forem arbitrárias. (STRECK, 2011, p 492)

Como resultado, afasta-se a arbitrariedade na construção de determinada verdade, pois esta passa a ser construída na relação sujeitosujeito/sujeito-sujeitos.

Sobre o tema, Luis Calos Santuário 4 aduz que a metafísica clássica (e até mesmo as pós-tradicionais) concebida na representação do humano como possuidor de uma racionalidade autônoma - o cogito cartesiano - foi suplantada pelo paradigma da linguagem (e que não necessariamente representa a morte do sujeito $^{5}$ - ou da subjetividade).

4 Quando percorremos o cenário filosófico e examinamos as estratégias de apresentação do espaço da clivagem, da diferença e da dobra na estrutura do humano, vemos que, inicialmente, na metafísica clássica, o humano havia sido definido pela sua capacidade de raciocinar. Esta representação do humano como ser racional. Como ser pensante, como cogito, tem sua coroação e refinamento na filosofia moderna, que produziu uma série de paradigmas, todos girando em torno da noção de um sujeito possuidor de uma racionalidade autônoma. Temos, assim, a instituição do solipsismo subjetivista de Descartes em que esta racionalidade opera de modo auto-suficiente e imanente e, posteriormente, a invenção do transcendental, do a priori, como terreno e armadura em que e como se efetiva a produção do conhecimento válido para o humano. Nestes dois filósofos (Descartes e Kant), o estabelecimento do modo e topos do conhecimento opera exemplarmente a partir da subjetividade, da consciência e, por conseguinte, da viciosa dicotomia sujeito-objeto. (SANTUÁRIO, Luiz Carlos, 2005, p. 149)

5 "Ela, a Filosofia da Linguagem, para o que aqui interessa, ao superar a Filosofia da Consciência, dá conta da relação sujeito-sujeito e não da relação sujeito-objeto. Por elementar, não se trata da decretação da morte da relação sujeito-objeto, muito menos da morte do próprio sujeito; e sim de admitir - em definitivo - a impossibilidade de, a partir de tal relação (sujeito-objeto) chegar-se em uma verdade Toda (e única) e sim tão-só em uma parte dela. A parte (daí a imparcialidade que move dita relação, sempre), todavia, não é o Todo e, portanto, é de outra coisa que se trata. (...) Embora ser grande a tentação - e interessantíssimas as conclusões de Melman e Lebrun -, do ponto de vista filosófico - e jurídico, como conseqüência e dentre outros -, se vinculadas a uma enunciação da "morte do sujeito", é de matriz insustentável. A constatação/descoberta de Freud, como se sabe, tem dimensão parecida; e que não se pode negar ou - seria melhor - desdizer. Contatar, porém a "morte do sujeito", hoje, não é desdizer só a Psicanálise, mas a própria realidade." (COUTINHO, 2010, p. 156) 
A invenção do transcendental clássico, de cunho kantiano, tem sua validade questionada e seu estatuto retificado e alterado pelo aparecimento da fenomenologia hermenêutica de Heidegger, a partir da predicação de um pré-compreender que, desde sempre, acompanha o humano em sua condição de sujeito situado no mundo. A dimensão estruturante, normativa e organizadora passa a ser agora a instancia de pré-compreensão e da finitude, deslocando a esfera de constituição e de estruturação do humano em um patamar solipsista e ligado a um cogito transcendental, para um instancia fenomenológica e hermenêutica. (...)

A fenomenologia hermenêutica pretende ter superado o transcendental clássico, ao interpretar o modo privilegiado de acesso ao conhecimento e a verdade como sendo possibilitado e efetivado pelo acesso e desenvolvimento do circulo hermenêutico, onde se mostra e se efetiva a diferença ontológica, círculo no qual esta diferença é pensada e reposta na linguagem. (SANTUÁRIO, 2005, p. 149-150)

Em sentido semelhante Habermas (2007, p. 7) defende a impossibilidade de integração dos dois paradigmas (do mentalismo e da linguagem), por entender o termo paradigma "em seu sentido estrito", mas não discordando na importância da subjetividade.

Deste modo, a estruturação de possíveis meios de participação democrática - e até mesmo dos meios de organização federativa - perpassam necessariamente por um contexto discursivo, portanto, reconhecendo o referido paradigma vigente a partir da virada ontológico lingüística.

A primeira relação se faz com o afastamento da arbitrariedade, como objetivo elementar, por exemplo, da liberdade como nãodominação. Philip Pettit (1999, p. 244) sustenta que, ao tratar das decisões públicas, estas não podem consistir em uma imposição arbitrária e que os cidadãos devem identificar nesta decisão o respeito aos interesses e interpretações compartilhados, devendo os que fazem as decisões responder por estas face aos afetados, outorgando à decisão inclusive um caráter democrático.

La toma pública de decisiones no puede representar una imposición arbitraria, entendida como tal por los ciudadanos. Tiene que proceder de tal modo, que podamos identificarnos con ella y acerla nuestra: que po- 
damos ver en ella promovidos nuestros intereses y respetadas nuestras interpretaciones. Ya sean las decisiones tomadas em la legislatura, administración o en los tribunales, tienen que llevar la impronta de nuestras inquietudes y de nuestros modos de pensar. (PETIT, 1999, p. 241)

A característica tratada é a de que o julgador e os agentes públicos passam a inserir-se em um contexto social para decidir, e não mais tão somente em sua própria concepção solipsista, hermética de verdade.

Outra relevante contribuição da perspectiva apresentada pela filosofia da linguagem se perfaz na estrutura dinâmica do republicanismo. Este dinamismo é o elemento que reconhece que a significação das coisas se constrói na intersubjetividade, tendo caráter transitório, e que Pettit entende como sistematicamente aberto e de reconstrução discursiva.

Nada tiene que estar en una posición tal, que otros puedan interferir en su vida guiados por intereses e interpretaciones no compartidos por él en ningún plano. (...) El criterio por el que reputamos arbitrario un ejercicio de poder, pues, es un criterio en sistemática evolución: sistemáticamente abierto a posibilidades de reconstrucción discursiva. (PETIT, 1999, p. 194)

E, apesar de tratar a tradição republicana de "império da lei", esta não importa necessariamente o império do código, sendo de extrema necessidade a interpretação hermenêutica de forma a conter arbitrariedades, interpretação aqui tratada como lingüística, histórica e culturalmente situada.

Para Habermas a mediação dos sentidos e das decisões públicas deve se constituir pela ação comunicativa, teoria por ele desenvolvida e pautada também no elemento hermenêutico, como afirma Marco Marrafon ${ }^{6}$.

\footnotetext{
6 "Por isso, em uma situação discursiva dialógica e reflexiva, é possível que o acordo surja quando os falantes/ouvintes possuam uma intenção comum: o entendimento de algo. Isso não é tudo. 0 elemento hermenêutico e a influência da filosofia de HEIDEGGER no pensamento habermasiano aparecem na força normativa da noção de mundo da vida que, através da abertura do "ser-no-mundo" se transforma em doador do conteúdo material que orienta o agir comunicativo." (MARRAFON, 2008, 71-72).
} 
A partir do agir comunicativo, fundado em uma teoria epistêmica da verdade e que se desdobra numa ética do discurso e em uma teoria da democracia e do direito, se reconhece que as práticas comunicativas estão vinculadas à aspectos culturais, sociais, à língua, etc., admitindo a complexidade das sociedades e a pluralidade de discursos (HABERMAS, 2007, p. 20).

Ainda assim, a construção de conceitos e de discursos válidos para a construção de uma cultura política devem se constituir intersubjetivamente, pautando, desta forma, a teoria habermasiana no paradigma lingüístico e, também, como um meio de orientação para a democracia. Pois, como sustentando anteriormente, Habermas não nega o sujeito e reconhece a complexidade dos aspectos culturais, mas pauta-se prioritariamente na formulação de que as verdades se desenvolvem a partir de uma construção discursiva. Para tanto, a fundamentação de uma ordem social só pode se dar a partir da compreensão deontológica da moral fundada no paradigma da linguagem.

Neste contexto, Habermas $(2003, \mathrm{p}$.) sustenta que "o modelo do contrato é substituído por um modelo do discurso ou da deliberação: a comunidade jurídica não se constitui através de um contrato social, mas na base de um entendimento obtido através do discurso. "Sendo que, tal discurso visa, por sua vez, a construção de um consenso normativo que seja capaz de formular normas válidas, que sejam - ou devam ser - reconhecidas pela coletividade.

Daí o porquê da edificação de uma cultura política única, mas que não negue nem oprima as subculturas, ou seja, que ela se constitua como única em formulações políticas, mas que mantenha abaixo desta as culturas minoritárias - sem exterminá-las ou excluí-las, possibilitando a constituição de uma sociedade multicultural.

Por outro lado, Dussel apresenta uma fundada crítica a respeito do paradigma da linguagem, visto que os consensos retratados por esta corrente teórica acabam por se demonstrarem meramente formais. Além desta constatação, ainda há de se considerar que o paradigma da linguagem, assim como os paradigmas do ser e do sujeito, sofre o mal da totalização.

Eis a constatação do filósofo argentino, a totalidade ontológica, e aí inclusa a "comunidade" pressuposta formalmente no agir comunicativo, aliena o Outro. 
Desde un punto de vista estrictamente filosófico hemos tratado desde finales del decenio de 1960 esta problemática, en lo que hemos denominado generacionalmente Filosofía de la liberación. Todo sistema (por supuesto también un sistema histórico concreto económico, como el capitalista) en algún momento se fetichiza, se totaliza, se transforma en lo que pudiéramos llamar una "sociedad cerrada", autorreferencial. Es la totalidad ontológica que aliena al Otro (el trabajo vivo o pueblo periférico) en el sistema como trabajo asalariado, o como colonia o país dependiente). (DUSSEL, 2014, p. 211)

Tal questão foi amplamente abordada por Celso Luiz Ludwig (2001, p. 97), em "Para uma Filosofia Jurídica da Libertação", em que deixa claro que "nos diferentes paradigmas a unidade figura como fundamento. Ela é o ser, o sujeito, o sentido, ou o não-ser, o não-sujeito e o não sentido". Neste contexto, a ontologia exprime o ser (do sistema vigente), e se apresenta como ideologia de dominação da periferia, do não-ser da totalidade.

Quanto ao agir comunicativo, resta evidenciado que o pobre (no campo econômico) é excluído da possibilidade de participar da comunidade argumentativa, assim como o terceiro mundo, nas relações internacionais é silenciado frente ao primeiro mundo, e assim em diante em cada campo.

Concretamente, o Terceiro Mundo é o silenciado na argumentação discursiva em relação ao Primeiro Mundo; nas estruturas do capitalismo periférico, é o pobre e socialmente o explorado e o silenciado, bem como o silenciado é o dominado em cada um dos níveis no interior do sistema (político, erótico, pedagógico, jurídico...). (...) Esse "pobre" não tem lugar na comunidade de argumentação argumentativa, porque faticamente excluído e silenciado. Em conseqüência, não busca acordo (consenso). Busca algo anterior: a condição de possibilidade de todo argumentar. (LUDWIG, 2011, p. 137)

Este excluído é sempre o Outro (a exterioridade), alguém que não participa dos consensos pressupostos pela teoria habermasiana e, que 
por outro lado, é o único capaz de realmente se opor ao consenso firmado na totalidade.

Por este motivo a ética proposta por Enrique Dussel não é uma ética do discurso, mas uma ética da alteridade, que leva em consideração a realidade material (corporalidade/dignidade) do Outro excluído do "universo" comunicativo real.

À Filosofia da Libertação interessa essa situação: o outro como condição
a priori de possibilidade de toda a argumentação, e, portanto, de todo
novo argumento. Trata-se do excluído, antes de ser afetado. Isso implica
levar em conta as condições materiais de possibilidade de participar -
deve-se levar em conta o poder efetivamente participar. A não-
comunicação - a incomunicabilidade (o não-ser) - é o ponto de partida. Na periferia do mundo latino americano, esse não é um tema apenas teórico, mas uma experiência fática que dura mais de um milênio. (LUDWIG, 2011, p. 107)

Neste viés, só a analética é capaz de reconhecer o sujeito que está além do horizonte da totalidade, onde a exterioridade é o meio de ruptura com a lógica da totalização em todos os campos e, conseqüentemente, sistemas. Portanto, há que se pautar a democracia na possibilidade de construção de consensos, formados pela participação efetiva dos sujeitos, contudo, há que se ter como prioridade a possibilidade de participação e do reconhecimento do Outro $^{7}$ e da libertação deste das diversas formas de dominação e exclusão.

\section{Globalização e a separação do poder e da política}

\footnotetext{
7 “A K.-O. Apel y a J. Habermas, por cierta ceguera con respecto al ámbito material en general (según he expuesto de la posesión "de lo a decidir" (es decir, de la condición de posibilidad de la simetría) y el hecho de la decisión sobre el contenido de lo que se argumenta, que los miembros de la comunidad no pueden dejarlo en manos de pretendidos expertos.

8 (...) En suma, el derecho ético a participar simétricamente es propio del argumentante como tal; es un a priori transcendental aceptado por el hecho de pretender llegar al consenso racional dando razones, como indica Apel. Pero dicho derecho sólo cobra fuerza de legitimidad real, jurídica, política, cuando se inviste al sujeto argumentante de ser propietario o miembro a parte entera de la comunidad institucionalizada política y económicamente. Sin esta fuerza de la ley el participante lo es en situación débil y parcialmente, ya que no podría defender el estado de derecho el poder efectivo de sua participación plena y de su decisión que no es simetrica." (DUSSEL, 2014, p. 259)
} 
Atentando para o Estado-nação e para as instituições contemporâneas, algumas constatações devem ser ressaltadas.

0 processo de globalização, além de decompor as fronteiras dos Estados-nação no âmbito da comunicação e do mercado, tornando o contato imediato com todo o planeta algo inevitável, trouxe outras conseqüências, dentre as quais a estruturação do modelo econômico neoliberal ${ }^{8}$, bem como a liquidez das certezas, das formas de vida, ou mesmo das instituições.

O insucesso das teorias de livre mercado e de Estado mínimo aplicadas ao redor do mundo, influenciados pelas doutrinas liberais "a direita do centro", ou libertarianas", demonstraram a falência de um modelo proposto como forma de substituição a um Estado que se demonstrava autoritário.

Ao revés, gerou novas formas de dominação. Os reflexos materiais da adoção destas práticas originaram maior desigualdade entre os países capitalistas, maior endividamento dos países de terceiro mundo, aumento do número de mortos em razão da fome, aumento do número de vítimas de guerra, agressão descontrolada ao meio ambiente, etc. (SANTOS, 2007, p. 24).

9 Para Philip Pettit, o fracasso das teorias liberais se deve ao conceito de liberdade (negativa) adotado: "La razón por la que el liberalismo clásico fracasa en este respecto es que el lenguage de la nointerferencia no alcanza más allá del sector de opinión e intereses del que primordialmente salió. El ideal liberal de ser dejado solo y en paz, en particular por parte del estado, cobro allás en los tempranos días del capitalismo industrial, como ideal para la nueva clase de empresarios y profesionales que buscaban beneficios. Para esos empresarios y para sus capeones, la noción de liberdad como no interferencia daba articulación a uma precondición indispensable para el êxito competitivo, y les resultó fácil pensar -desde luego, les resultó muy conveniente pensar- que la noción representaba um ideal universalmente atractivo. Pudieron ignorar el hecho de que la liberdad como no-interferencia es compatible com la inseguridad, con la falta de estatus y con una necesidad de observar trayectorias cautelosas en las cercanías de los poderosos." (PETIT, 1999. p. 177). Já Álvaro de Vita sustenta que tais teorias estão vinculadas prioritariamente a uma noção de propriedade, e não de liberdade. Primeiramente argüindo que "A tese central da filosofia política libertariana não diz respeito, diretamente à liberdade, e sim a propriedade (p. 59)." Depois arrazoa que "A preocupação primeira de Nozick, portanto, não é com a liberdade individual, mas com a inviolabilidade do direito moral de propriedade de si próprio e dos recurso externos obtidos por meios permissíveis (p. 60)." (VITA, 2007, Cap. 2). 
Dentre outras, as relações de dominação entre países e a ingerência nas políticas internas por outros Estados-nação também deflagram formas de dominação.

Quanto as pessoas, individualmente tratadas, Boaventura de Sousa Santos adverte que as expectativas com o futuro tem sido incertas e deficitárias em relação às experiências presentes, por mais medíocres que sejam essas experiências ${ }^{10}$ :

No final do século, a globalização neoliberal e o capitalismo neoselvagem vieram alterar esta condição. Para a esmagadora maioria da população, a discrepância entre experiências e expectativas mantém-se, mas invertida: as expectativas são agora negativas e deficitárias em relação às experiências. (SANTOS, 2007, p. 34)

Neste contexto, Zygmunt Bauman tem sustentando a ocorrência da separação do poder e da política, que desde o nascimento do Estado moderno têm se contido nas mãos do Estado-nação. Sendo que, neste momento, o poder passou exercido no espaço global, enquanto a política permaneceu local e, portanto, incapaz face o primeiro.

A legitimidade do corpo político em sua forma atualmente mais comum e Estado-nação está em apuros, e assim é necessário procurar urgentemente uma legitimação alternativa.

$[\cdots]$

Num planeta negativamente globalizado, todos os principais problemas - os metaproblemas que condicionam o enfrentamento de todos os outros - são globais e, sendo assim, não admitem soluções locais. Não há nem pode haver soluções locais para problemas originados e reforçados globalmente. A união do poder e da política pode ser alcançada, se é que pode, no nível planetário. (BAUMAN, 2007, p. 21)

Neste mesmo sentido tem sustentado Zygmunt Bauman, alegando que "O progresso se transformou em uma espécie de dança das cadeiras interminável e ininterrupta, na qual um momento de desatenção resulta na derrota irreversível e na exclusão irrevogável. Em vez de grandes expectativas e sonhos agradáveis, o "progresso" evoca uma insônia cheia de pesadelos de "ser deixado para trás" se perder o trem ou cair da janela de um veículo em rápida aceleração. [...] tentamos calcular o risco que nós, pessoalmente, ou aqueles que nos são mais próximos e queridos no momento, possamos nos tornar vítimas dos incontáveis perigos do mundo opaco e seu futuro incerto supostamente têm guardado para nós." (BAUMAN, 2007, p. 17). 
Os primeiros avanços na estruturação de uma organização política supranacional, com, inclusive, a cessão de parte da soberania do Estado nacional, desenvolveram-se na União Européia e, para Habermas foram desencadeados por três momentos históricos ${ }^{11}$ : a unificação alemã, a aproximação dos Estados da comunidade européia e os fluxos imigratórios que imprimiram uma "nova guinada numa discussão (...) sobre a sociedade pós-nacional".

Para o frankfurtiano (2003, p. 280-281) "a dissolução das chaves semânticas que definem a cidadania e a identidade nacional corresponde ao fato de que a forma clássica do Estado Nacional se encontra hoje em dissolução, à medida que a Comunidade Européia se transforma numa união política."

Norberto Bobbio (2001, p. 17), em textos publicados no pósguerra, já elaborava ensaios sobre o desenvolvimento de um federalismo europeu, argüindo inclusive que a sua efetivação dentro e fora do Estado são elementares para a garantia da liberdade:

Ou se dissolve o Estado unitário em autonomias, ou a federação européia é impraticável. Ou se encaminha a política européia para fora do pântano da política de prestígio nacional, ou, de outra maneira, o princípio autonomista permanece letra morta. Federalismo internacional e federalismo estatal são dois processos absolutamente independentes: o princípio federativo deve agir por dentro e por fora para desmantelar o rochedo do Estado unitário. Agir somente por dentro ou somente por fora conduz a política federalista a uma inevitável falência.

11 "Três momentos históricos desse período, que entrou em ebulição, mexem com a relação entre cidadania e identidade nacional: (1) A unificação alemã, seguida pela liberação dos Estados da Europa Central Oriental da tutela soviética e pelos conflitos de nacionalidade que estouraram em todo o Leste Europeu, recoloca a questão acerca do Estado Nacional. (2) A aproximação entre os Estados da Comunidade Européia, especialmente através do mercado interno, que entrará em vigor a partir de 1993, coloca numa nova luz a relação entre Estado nacional e democracia, pois os processos democráticos construídos em nível de Estado nacional, não conseguem atingir o nível de integração econômica realizada em nível supranacional. (3) Os gigantescos fluxos migratórios que se original nas regiões pobres do Leste e do Sul, a serem enfrentados pela Europa Ocidental nos próximos anos, conferem ao problema dos asilados uma nova importância". (HABERMAS, 2003, p. 279) 
Neste viés, resta evidente que novas formas de organizações políticas (de caráter regional) não só poderão como deverão surgir, dando origem a novas maneiras de se conceber as instituições e a democracia em um âmbito supranacional.

A partir de um caminho semelhante, Philip Pettit (PETIT, 1999. p. 201) tem defendido que o ideal de liberdade como não-dominação não pode estar definido em determinadas instituições (como as já préexistentes nos Estados-nação). E, diante do contexto em que estamos inevitavelmente inseridos, julgou ser atrativo aos Estados republicanos vincularem-se por cooperações de caráter multinacional.

0 que demonstra o horizonte é que teremos instituições de caráter internacional, ainda que permaneçam as estruturas dos Estadosnação. Paul Ricoeur, inclusive, entende que ambos serão fontes criadoras de direito:

Não será menos difícil, nas próximas décadas, conciliar a indivisível soberania popular com a proliferação de uma multidão de focos de direito, tanto quanto conciliar essa mesma indivisível soberania com as novas instituições pós-nacionais, senão supra-estatais, que também elas, engendrarão direito. Assim como precisaremos gerir uma situação simétrica oriunda da imbricação de varias fontes de juridicidade no nível infraestatal; essa situação resulta da figura apresentada pelo paradoxo político. (RICOEUR, 2008, p. 132)

O problema das experiências de organização internacional dos Estados diz respeito ao seu caráter prioritariamente econômico, que muitas vezes relega a política para segundo plano e condiciona a atuação às lógicas econômicas, nem sempre (ou quase nunca) relacionadas à satisfação de direitos.

Nesta direção, Habermas (HABERMAS, 2003, p. 280-291) considera que muito se lamentou pela falta de democracia no processo de unificação que foi realizado na União Européia, no nível administrativo e econômico, sem a participação dos cidadãos. Contudo, apesar do déficit democrático, o frankfurtiano insiste que a comunidade Européia Econômica Européia manifesta vontade de formar uma União Política Européia. 
Ainda quanto aos empecilhos na estruturação de uma democracia regional, Jürgen Habermas apresenta as considerações de que os Estados nacionais constituem um problema para a consolidação do bloco político, não em razão da soberania, mas em virtude de seus processo democráticos só funcionarem no interior de suas fronteiras. Fora delas, somente se cria um mercado comum, composto por mecanismos administrativos e jurídicos e o parlamento continua relegado à segundo plano, cerceado em suas competências.

Tal constatação da submissão da política à economia também pode ser vista na periferia do mundo, mas com uma peculiaridade histórica de que a periferia é, desde o século XVI, dominada na geopolítica mundial, o que ainda hoje se expressa no capitalismo dependente.

Pareció a algunos que la Teoria de la dependência fue solo una formulación propia del pasado, del decenio de los sesenta del siglo XX. Nos es así. Se encuentra en el corazón mismo de la teoría de Wallerstein del llamado World-System, y aun del hecho de la globalización actual del capital (y explica los motivos de una reciente tendencia a la des-globalización). $\mathrm{Su}$ pertinencia no ha perdido nada de su importancia y por ello su ausencia se deja ver en la ambigüedad com la que la misma izquierda trata esos temas. Es la clave todavía del proceso de liberación económica, política y cultural de las periferias (mundial y nacional) en referencia a los antiguos y emergentes nuevos centros del capitalismo. (DUSSEL, 2014, p.165)

Esta dependência ${ }^{12}$ intensifica os efeitos da economia frente à política, uma vez que a própria economia nacional é historicamente fragilizada, dependente, e, portanto, vitima da transferência de valor para os

12 “Por su parte, el capital periférico es el capital global de los países que fueron colonia o que han realizado la Revolución industrial posteriormente a los países desarrollados, situados lejanamente de los capitales centrales, con una composición orgánica inferior a ellos, y dominados sistémica o estructuralmente por la extracción de plusvalor cuya causa, en el espacio de la competencia mundial, es analizada y explicada por la Teoría de la dependencia. La situación de dependencia impide un desarrollo, no sólo capitalista sino en general de los países subdesarrollados (por transferencia estructural continua de plusvalor), faltos de acumulación originaria suficiente y de posibilidades objetivas para realizar en el horizonte de la fronteras del Estados periférico sus excedentes." (DUSSEL, 2014, p.167) 
países centrais, o que a submete/submeteu às influências dos países centrais (colonialismo) e hoje do capitalismo central.

Avaliando que o caminho para a consolidação de um federalismo externo é (ainda que as experiências até o momento sejam incipientes) um caminho sem volta - e necessário, se ponderada sua organização como meio de controle do poder econômico ${ }^{13}$-, cabem às investigações da filosofia política abrir terreno para a construção de mecanismos republicanos supranacionais - e, a partir daí, a importância da fundamentação em métodos discursivos, mas principalmente pautado pelo momento ético da exterioridade.

Ademais, além da organização institucional, este debate perpassa pela afetação da soberania estatal e, inclusive, pela relação entre cidadania, nacionalidade e alteridade.

\section{Acoplamento estrutural e razão transversal - a interferência de um campo sobre outro}

A influência da economia sobre a política, no contexto delineado acima, pode ser analisada a partir do acoplamento estrutural.

Primeiramente, deve-se pontuar que, para Marcelo Neves (2009, p. 25), a política ${ }^{14}$ não encontra lugar privilegiado na teoria dos sistemas, e não opera em nenhuma hipótese como um "supersistema". É, em realidade, um sistema em concorrência com os outros.

Por outro lado, Neves alega que a economia constitui na sociedade capitalista mundial o fator mais relevante, não por uma "ontologia essencial", mas pelos diversos motivos já elencados anteriormente, dentre eles a possibilidade de transpassar as fronteiras nacionais e se organizar de forma global.

13 Sobre poder econômico organizado em escala global, Bauman referencia os estudo de Hobsbawm:“O que temos hoje é, com efeito, um sistema dual, o sistema oficial das "economias nacionais" dos Estados, e o real, mas não oficial, das unidades e instituições transnacionais ... Ao contrário do Estado com seu território e poder, outros elementos da "nação" podem ser e são facilmente ultrapassados pela globalização da economia. Etnicidade e língua são dois exemplos óbvios. Sem o poder e força coercitiva do Estado ,sua relativa insignificância é clara." (HOBSBAWM Apud. BAUMAN, 2011, p. 219)

14 Inclusive, para Gunther Teubner, a política foi ultrapassada por outros sistemas sociais: "Na via da globalização, a política foi claramente ultrapassada pelos outros sistemas sociais [...], não apenas perdeu seu papel de liderança, mas regrediu nitidamente em comparação com outros âmbitos parciais da sociedade". (TEUBNER Apud. NEVES, 2009, p. 33) 
Embora a sociedade mundial não possa ser identificada economicamente com o sistema capitalista mundial no sentido de Immanuel Wallerstein, pois ela é multicêntrica, cabe defini-la como uma sociedade que se desenvolve primariamente com base nas expectativas cognitivas (economia, ciência e técnica). Formulando de maneira mais específica, ela pode ser caracterizada por "um primado social da economia" ou como uma "sociedade econômica". Não se trata de um primado "ontologicamente essencial" nem forçosamente de perda da autonomia dos outros sistemas sociais, mas cumpre considerar que, nos ambientes dos diversos sistemas parciais da sociedade mundial (moderna), a economia (associada a técnica e à dimensão da ciência a esta vinculada) constitui o mais relevante fator, a ser observado primariamente. (NEVES, 2009, p. 28)

Semelhante à economia, também se desenvolvem outros campos, como o campo semântico, orientado pelos meios de comunicação de massa, ilimitado territorialmente. Daí a distinção face à política, que embora semelhante em escala mundial, se organiza segmentada territorialmente, dentro dos limites de cada Estado nação.

Conforme Luhmann, essa segunda diferenciação do sistema político, condicionada estatalmente, persiste hodiernamente porque os pressupostos para a legitimação política ainda estão vinculados aos contextos regionais, não havendo perspectivas de uma política mundial abrangente que possa prescindir da formação de Estados. (NEVES, 2009, p. 31)

A questão primordial para a política, e que determina tal situação, é a exigência de legitimação, ou seja, de meios/instrumentos democráticos que outorguem validade as decisões políticas.

Para a teoria dos sistemas, a razão transversal é a razão cuja linguagem é passível de realizar pontes de transição entre os sistemas heterogêneos, e são sempre razões transversais parciais, na medida em que dão conta somente de parte da linguagem própria de outro siste- 
ma. ${ }^{15}$ Este contato entre sistemas e sua inter-relação é denominado acoplamento estrutural.

Essa relação inter-sistemática é comum e necessária. Contudo, possui o lado negativo, que consiste em um sistema bloquear a autonomia sistêmica de outro. Este é, portanto, o ponto em que se encontra a política, condicionada/corrompida pelo sistema econômico.

O lado negativo do acoplamento estrutural são bloqueios recíprocos das autonomias sistêmicas mediante corrupção dos sistemas envolvidos. Aqui o código de um dos sistemas é sabotado pelo código de um outro sistema, de tal sorte que aquele perde a sua capacidade de reprodução consistente. Assim, se o código "ter/não ter" (economia), por via do processo eleitoral ou dos procedimentos fiscais e tributários, corromper as regras do jogo democrático, sabotando diretamente o código da política (diferença governo/oposição construída democraticamente), dar-se-á a corrupção sistêmica se houver incapacidade do sistema político de reagir, conforme seus próprios critérios e programas, a sobreposição da política.

(...) E o problema torna-se grave, em contextos sociais da sociedade contemporânea hipercomplexa, quando a corrupção estrutural de um sistema por outro(s) tem um tendência à generalização. (...) No âmbito da teoria dos sistemas, referi-me a essa situação como caso de alopoiese do direito; isso significa que esse sistema é determinado diretamente (não apenas condicionado) por outro(s), sendo incapaz de uma autoprodução consistente ou fechamento operativo. (NEVES, 2009, p. 32)

Enfim, deste lugar é possível compreender teoricamente a necessidade de fortalecimento do campo político, pelo fortalecimento das instâncias políticas supranacionais.

15 "Todo âmbito de comunicações, ao pôr-se em conexão com um outro, pode desenvolver seus próprios mecanismos estáveis de aprendizado e influência mútuos. Então, cabe falar de racionalidades transversais parciais, que podem servir à relação construtiva entre as racionalidades particulares dos sistemas ou jogos de linguagem que se encontram em confronto. Cada racionalidade transversal parcial está vinculada estruturalmente às correspondentes racionalidades particulares, para atuar como uma "ponte de transição" específica entre elas." (NEVES, 2009, p. 42) 


\section{Considerações sobre as experiências européias e latino ameri- canas}

Muito tem se sustentado que a União Européia tenha se transformado ao longo dos anos em um modelo burocrático. Segundo avalia Reiner Nickel (2007, p. 151), tal burocracia se origina devido a estrutura da UE, que possui duas faces. Uma "oficial" caracterizada pelo Parlamento Europeu, pelo Conselho, pela Comissão e pela Corte de Justiça e, por outro lado, uma face menos visível, caracterizada pelos comitês ("comitologia"), onde sucessivamente são tomadas decisões burocráticas. Neste sentido, as decisões da União Européia carecem de controle (accontability), embora tenha se pensado a UE como um projeto constitucional.

Segundo Nickel (2007, p. 169), as fusões das funções legislativas e executivas levaram a União Européia a funcionar na sombra da lei, pautada em decisões de burocratas com preferências e interesses pessoais, ainda que tal estrutura derive da própria legislação.

Neste mesmo sentido pondera Marcelo Neves (2009, p. 104), constatando que "o frágil parlamento europeu ainda não tem poderes que o tornem capaz de avaliar e selecionar mediante uma discussão transparente, conteúdos normativos oriundos dos processos de deliberação nos grêmios profissionais e comitês técnicos."

Verifica-se, neste viés, que a União Européia tem avançado na constituição de um modelo supranacional, com instituições executivas, legislativas e judiciárias, bem como o estabelecimento da zona do euro, a abertura de fronteiras para fluxos de cidadãos dos países membros, etc. Por outro lado, tem se constituído como um modelo burocrático e tecnocrata (reflexo da "comitologia"), que coloca em cheque seus valores democráticos originários.

Relacionado a essas questões, Slavoj Zizek aduz que a UE é um projeto de administração (tão somente), incapaz de mover paixões necessárias ao preenchimento do "vazio democrático". ${ }^{16} \mathrm{E}$ que nenhuma

16 “Não me admira que o projeto europeu, amplamente debatido hoje, não consiga despertar paixões: em última análise, é um projeto de administração, não de compromisso ideológico. A única paixão é a reação da direita contra a união da Europa; nenhuma das tentativas da esquerda de infundir paixão política na noção de um Europa unida (como a iniciativa de Habermas e Derrida no verão de 2003) conseguiu ganhar impulso." (ZIZEK, 2011, p. 116) 
das tentativas (à exemplo de Habermas e Derrida) em difundir o ideal de uma Europa unida foram bem sucedidas.

Tal pretensão administrativa possivelmente está vinculada as motivações fundantes, tanto do Mercosul17, quanto da EU (que apesar de se dizer um projeto constitucional), que dirigiam-se a criação de um mercado comum, sendo, ao que parece, este o ponto comum entre ambos os projetos, ou seja, de um projeto econômico com dificuldades de implementação de uma legitimação democrática autêntica (NICKEL, 2007, p. 151).

Contudo, os empecilhos para cada experiência tem sido diversos. Enquanto a Europa é incapaz de fugir do modelo burocrático, a América Latina tem a dificuldade em estabelecer um equilíbrio de desenvolvimento entre os estados membros.

Para a construção dos modelos supranacionais, Marcelo Neves pondera a necessidade de um nível de desenvolvimento simétrico ${ }^{18}$, que parece ter sido alcançado de certa forma pela União Européia. ${ }^{19}$

Por outro lado, tal situação não se repete na América Latina:

Embora interdependentes essas duas dimensões já no plano do Estado de direito, as deficiências presente nos Estados-membros prejudicam a formação de um direito interno sul-americano no plano do Mercosul, além de a estrutura deste ser incompatível não só com a legitimação democrática, mas também com a construção de uma política interna sulamericana. (...) Pode-se falar também de um duplo déficit de Estado de

17 Apesar de não se tratar da única experiência latino-americana, optou-se por versar sobre o Mercosul por ser a experiência mais desenvolvida e sedimentada, não se negando a existência de outras experiências existentes mais incipientes.

"Parece plausível que uma certa simetria no nível de desenvolvimento dos respectivos Estadosmembros é uma condição decisiva para a construção de uma supranacionalidade, que implica normas e decisões abrangentes nas dimensões social, material e temporal, vinculando diretamente os cidadãos e órgãos estatais. Nos casos de condições orçamentárias, níveis educacionais, sistemas de saúde, situação de trabalho e emprego etc. muito dispares, fica obstaculizada ou, no mínimo, dificultada a incorporação normativa imediata (sem ratificação) que caracteriza uma ordem supranacional." (NEVES, 2009, p. 99)

19 "Os esforços da União Européia para que fosse alcançado um certo nível mínimo de equilíbrio orçamentário por parte dos Estados que se candidatam ao ingresso na qualidade de membros e os correspondentes controles depois da admissão dos respectivos Estados (trata-se, ao menos, de uma exigência formal para a admissão na zona do Euro) são indícios de que, diferentemente do caso da internacionalidade, uma supranacionalidade estável não suporta grandes disparidades de desenvolvimento." (NEVES, 2009, p. 99-100) 
Direito (orientado pelo princípio da igualdade), que prejudica a limitação e o controle jurídicos dos agentes públicos e privados tanto no plano dos Estado Partes quanto no plano dos órgãos intergovernamentais. (NEVES, 2009, p. 101.)

Deste modo, a disparidade de desenvolvimento entre os Estados membros tem se tornado um grande empecilho o fortalecimento de organizações supranacionais latino-americanas.

\section{Considerações finais}

Constata-se que as iniciativas de criação de organizações regionais supranacionais partiram da ocorrência da separação do poder e da política, ocasionado pelo processo de globalização negativa, em que o poder passou a ser exercido no espaço global, enquanto a política permaneceu local e, portanto, incapaz face ao primeiro. Há certamente um desgaste na relação entre capitalismo e democracia.

Dentre seus efeitos, está a criação da UE e do Mercosul, pautados prioritariamente no intuito de integração dos mercados regionais comuns, como forma de defesa e fortalecimento face à economia globalizada.

Resta saber até que ponto podem estes agrupamentos supranacionais tomar suas decisões políticas e como estabelecer efetivos níveis de republicanismo e democracia além das fronteiras do Estado-nação, sendo a resolução deste desafio a forma possível de contenção da determinação da política pelo campo econômico.

\section{Referências}

BAUMAN, Z. Modernidade Líquida. Rio de Janeiro: Jorge Zahar, 2011.

. Tempos Líquidos. Rio de Janeiro: Jorge Zahar, 2007.

BOBBIO, N. Entre Duas Repúblicas: às origens da democracia italiana, Brasília: Universidade de Brasília, 2001.

COUTINHO, J. N. de M. In: Direito e Psicanálise: Intersecções a partir de "O Mercador de Veneza" de William Shakespeare, $2^{\text {a }}$ Tiragem, Rio de Janeiro: Lumen Iuris, 2010. 
DUSSEL, E. 16 Tesis de Economía Política: Interpretación Filosófica. México: Siglo XXI Editores, 2014.

GANHO, L. G. A Disputabilidade e o Financiamento de Campanhas Eleitorais no Brasil: Uma análise perante a teoria neorrepublicana. Revista Estudos Eleitorais, vol. 8, nำ 2, maio/agosto 2013.

HABERMAS, J. A ética da discussão e a questão da verdade. $2^{\text {a }}$ Ed. São Paulo: Martins Fontes, 2007

Direito e Democracia: entre facticidade e validade II, $2^{\text {a }}$ Ed, Rio de Janeiro: Tempo Brasileiro, 2003.

LUDWIG, C. L. Para uma Filosofia Jurídica da Libertação: Paradigmas da filosofia, filosofia da Libertação e Direito Alternativo. 2a Ed., São Paulo: Conceito Editorial, 2011.

MARRAFON, M. A. Discursos sobre a verdade, radicalização hermenêutica e fundação ética: o caráter complexo do método jurídico na decisão constitucional. Curitiba, 2008. Tese (Doutorado em Direito do Estado) - Setor de Ciências Jurídicas, Universidade Federal do Paraná.

NEVES, M. Transconstitucionalismo. São Paulo: WMF, 2009.

NICKEL, Rainer. Governance, Democracy, and Judicial Control in the EU - The European Court of Justice and the EU Committees. In: MATIASKE, W. et al. The European as a Model for Development of Mercosur?, vol. 4, Muenchen: Rainer Hampp Verlag, 2007.

PETIT, P. Republicanismo: Una teoria sobre la libertad y el gobierno, 1aㅡ Ed, Barcelona: Paidos, 1999.

RICOEUR, P. 0 Justo 1: A justiça como regra moral e como instituição, 1aㅡ Ed, São Paulo: WMF Martins Fontes, 2008.

SANTOS, B. de Sousa. A Crítica da Razão Indolente: Contra o desperdício da experiência, Vol. 1, 6aㅡ Ed., São Paulo: Cortez, 2007.

SANTUÁRIO, L. C. Filosofia e psicanálise: A linguagem em Lacan, Apel e Gadamer. Revista de Filosofia, Curitiba, v. 17, no 20, p. 147-163, jan/jun 2005.

STRECK, Lenio Luiz. Hermenêutica Jurídica e(m) Crise: Uma exploração hermenêutica da construção do Direito, 5ํㅡㄹ Ed., Porto Alegre: Livraria do Advogado Editora, 2004.

. O Sentido Comum Teórico dos Juristas e o "Princípio" da "Verdade Real": 0 ponto de encontro entre o solipsismo com o arbítrio. Revista de Estudos Criminais, Porto Alegre: PUCRS, Janeiro/Março 2012. 
. Verdade e Consenso: Constituição, hermenêutica e teorias discursivas. $4^{\underline{a}}$ Ed, São Paulo: Saraiva, 2011.

VITA, A. de. Justiça Igualitária e Seus Críticos. 1a Ed., São Paulo: Martins Fontes, 2007.

ZIZEK, S. Em Defesa das Cuasas Perdidas. São Paulo: Boitempo, 2011.

Recebido: $15 / 12 / 2014$

Received: $12 / 15 / 2014$

Aprovado: 19/12/2014

Approved: 12/19/2014 